\title{
Job Stress in Young Physicians with an Emphasis on the Work-Home Interface: A Nine-Year, Nationwide and Longitudinal Study of its Course and Predictors
}

\author{
Jan Ole RØVIK*, Reidar TYSSEN, Erlend HEM, Tore GUDE, \\ Øivind EKEBERG, Torbjørn MOUM and Per VAGLUM
}

Department of Behavioural Sciences in Medicine, Institute of Basic Medical Sciences, Faculty of Medicine,
University of Oslo, P.O. Box 1111 Blindern, NO-0317 Oslo, Norway

Received March 27, 2007 and accepted June 27, 2007

\begin{abstract}
Although physicians are known to experience more stress than other workers, knowledge is lacking on the course of stress from a longitudinal perspective. This study explored the course of and contributors to, different dimensions of early career job-stress among physicians by means of a nationwide mail survey, with a particular emphasis on stress relating to the work-home interference. All physicians graduating from all four Norwegian universities in 1993 / $94(\mathrm{~N}=631)$, responded during their final year of medical school $(\mathrm{N}=522)$, during their internship $(\mathrm{N}=402)$, in their 4th postgraduate year $(\mathrm{N}=422)$, and in their 10th postgraduate year $(\mathrm{N}=390)$. The mean observation period was $9.2 \mathrm{yr}(\mathrm{SD}=0.5)$. The main outcomes were job stress dimensions derived from an established job stress questionnaire (Cooper / Tyssen), with emphasis placed on dimensions of the work-home interference. Stress relating to the work-home interference increased during the observation period for both genders (repeated measures: $\beta=0.06, p<0.05$ ), whereas stress relating to emotional pressure, time pressure, and fear of complaints and criticism, decreased. Stress relating to the work-home interference increased during their early career, mainly due to a lack of adaptive reduction in work hours and an increased number of children. Neuroticism, conscientiousness, and lack of support from one's partner and colleagues, appeared to be predictive of this stress.
\end{abstract}

Key words: Colleague, Job stress, Overtime, Physician, Spouse, Support, Working hours, Work-home interface

\section{Introduction}

Knowledge about work-related stress is crucial for identifying risk factors for mental distress and burnout among physicians, and fostering sound working environments in health care institutions that will ensure appropriate patient care $^{1,2)}$. Several studies have described a high level of perceived stress among physicians ${ }^{3-6}$, but none have explored the longitudinal course and character of work-related stress from internship to residency, and then as a working physician, particularly in a nationwide cohort. Different studies point

\footnotetext{
*To whom correspondence should be addressed.
}

to a high level of work-related stress early in the career of physicians ${ }^{5,7,8)}$. Less is known about stress later in their careers however. Four work-related domains are commonly reported in physician stress: overwork / workload $^{4,9)}$, demanding patient work $^{9-12)}$, time pressure ${ }^{10,13,14)}$, and difficulties in handling the work-home interface ${ }^{10,15,16)}$. Nevertheless, the relative importance of these factors may vary by gender, and in different phases of the medical career $^{10,13)}$. Work-home conflict is related to several negative outcomes, including burnout, work-related stress, and psychological strain ${ }^{17)}$, depression ${ }^{18)}$, sleep deprivation and physical complaints ${ }^{19)}$. Such stress should therefore be studied prospectively in nationally representative samples. 
Support from colleagues may influence physician stress ${ }^{20,21)}$, as well as long hours. Long standing experience of stress from the work-home interface has been shown to be responsible for the deterioration of health in physicians ${ }^{222}$. Less is known about support from the physician's spouse, the relative influence of support from colleagues, as well as support from the spouse in explaining stress related to the work-home interference at different steps of one's postgraduate career.

We have prospectively studied the predictors of stress related to the work-home interference in a nationwide cohort of young doctors. There has been no other large prospective study of emotional distress among female physicians, except one study of general practitioners ${ }^{23)}$, although we expect that women may be more exposed to such stress. Even in a Scandinavian country with reasonably equitable working conditions across the genders, women still experience a greater total workload because they incur greater domestic responsibilities than men $^{24)}$. We also expect that personality traits may be important ${ }^{25,26)}$, and have recently found that both neuroticism and conscientiousness may predict stress at medical school level ${ }^{27)}$, and that neuroticism is a major predictor of general work stress during internship ${ }^{28)}$.

However, we have not studied stress beyond internship or controlled for other possible stress factors, such as the number of children and total working hours per week in a repeated measures predictor model. We would expect these factors to be of importance among young doctors striving to balance their work and home life. Although, both the number of working hours and the number of children are measured and reported concurrently, they are quite "solid" and may be expected to be relatively little influenced by concurrent stress. Based on previous research our main hypothesis is that stress related to competence in clinical work (emotional exhaustion and time pressure) will decrease over the years with experience, whereas balancing work and home life will remain a stress factor, in particular among female physicians ${ }^{24,25,29)}$. We are more uncertain whether fear of litigation is an important stress factor among Norwegian doctors, as legal action for malpractice occurs rarely ${ }^{30}$.

Against this background, we have conducted a 9-yr prospective, longitudinal study of all Norwegian physicians who graduated in 1993 or 1994 (N=631). Participants were surveyed 4 times from the last year of medical school to the 10th postgraduate year. However, as different factors of the stress in question may vary in importance over the years, we have explored the levels of 4 work-related stress dimensions separately and, in particular, studied predictors of stress related to work-home interference. Our research questions were therefore, as follows.

1. What is the course of perceived job stress over the first 9 years of physicians' career, and in particular stress related to the work-home interference?

2. To what extent can stress related to work-home interference be predicted by personality and gender, as well as by demands such as working hours and number of children, and resources such as support from spouse and colleagues?

\section{Subjects and Methods}

\section{Participants}

A national cohort of all physicians who graduated from the 4 medical schools in Norway in 1993 or $1994(\mathrm{~N}=631)$ was surveyed by postal questionnaire at 4 time points: $\mathrm{T} 0$, the final year of medical school (T0, N=522/631, 83\% of the total sample), T1, internship, 1 yr after graduation ( $\mathrm{N}=402$ / $631,64 \%), \mathrm{T} 2$, the 4 th postgraduate year $(\mathrm{N}=422 / 631,67 \%)$, and the 10th postgraduate year $(\mathrm{N}=390 / 631,62 \%)$. The mean ages at T0, T1, T2, and T3 respectively were $28,29,31$, and $37 \mathrm{yr}$, with no significant gender differences. The mean observation time was $9.2 \mathrm{yr}(\mathrm{SD}=0.5)$. Dropout analysis, by independent sample $t$-tests, revealed no significant differences in any of the job stress dimensions at T1, or any of the independent variables between dropouts and nondropouts.

\section{Dependent variables}

Perceived job stress was measured at 3 time points (1st, 4th, and 10th postgraduate year) with a modified version of the Cooper Job Stress Questionnaire (Cooper, 32 items selfreport, modified by Tyssen $\left.{ }^{10,12}\right)$. The physician was presented with a series of situations and asked to rate the degree of stress experienced on a scale from 1 (Not at all) to 5 (Very much).

A factor analysis with varimax rotation was conducted on the T1 data. Based on items that loaded more than 0.4 on one factor, and the deletion of items with loading differences of less than 0.2 between factors, 4 scales were constructed: (1) Stress related to emotional pressure in patient work, e.g., 'I am stressed by dealing with suffering patients' (Cronbach's $\alpha=0.83$ ); (2) Stress related to time pressure, e.g., 'I am stressed by interruptions and fuss' (Cronbach's $\alpha=0.75$ ); (3) Stress related to fear of complaints and criticism, e.g., 'I am stressed by the possibility of complaints from patients', 'I am stressed by the possibility of conflicts with my colleagues' (Cronbach's $\alpha=0.73$ ); (4) Stress related to interference with family and social life, consisting of 3 items: 
'I am stressed by the job interfering with my family life', 'I am stressed by problems with balancing job and private life', 'I am stressed by the job interfering with my social life' (Cronbach's $\alpha=0.83$ ).

\section{Predictor variables}

Age was measured as a continuous variable in years. Gender was coded 1 for women and 2 for men. Personality traits were measured at $\mathrm{T} 0$ and $\mathrm{T} 1$, in randomly selected halves of the sample by using the 27-item version of Torgersen's Basic Character Inventory ${ }^{12,31)}$ assessing the "big three" personality dimensions of neuroticism (low general self-esteem, self-criticism), extraversion, and conscientiousness. Each dimension was measured by dichotomous response (agree/do not agree) on 9 questions, and was scored as a total score with a range from 0 (low) to 9 (high), thus giving a continuous variable. Regarding the weighting of items making up the scales we have performed ancillary analyses on each scale extracting the first principal component from the same set of items that make up the scale. The factor scores thus derived correlate $0.996,0.950$, and 0.972 with the unweighted scales of neuroticism, extraversion, and conscientiousness respectively. This shows that in practice the unweighted scales used by us tap the same underlying dimensions as that derived from the principal component analyses (i.e. the versions weighted by the factor score coefficients). Cronbach's $\alpha$ for the scales in this sample were: neuroticism $=0.82$, extraversion $=0.87$ and conscientiousness $=0.63$.

Concurrent explanatory variables measured at the 1st, 4th, and 10th postgraduate year

Number of working hours per week was measured as a continuous variable. Number of children was assessed on a 4 point scale: no children; 1 child; 2 children; 3 or more children. Spouse support was measured using a rating scale with 4 items on emotional and instrumental spouse support as well as spouse's acceptance of physician's working schedule (e.g. 'When the job situation is bad, I find comfort and support in my spouse'; 'My spouse thinks I work too much' (reversed)), using a scale from 1 (Is not at all the case) to 5 (Is absolutely the case). Cronbach's $\alpha$ was 0.66 . Colleague support was measured using a rating scale consisting of two questions: 'To what degree are you taken care of by your colleagues?', and 'To what degree do you enjoy working with your colleagues?', using a scale from 1 (Not at all) to 7 (To a very high degree). Cronbach's $\alpha$ was 0.84 . The adequacy of the use of linear scores of ordinal data in our study was demonstrated with the appropriate tests recommended by Cox \& Wermouth ${ }^{32)}$. For each independent variable we examined non-linearity in regression by including both the independent variable and its square. A quadratic contribution was found for conscientiousness. Thus, the square of conscientiousness was included in the regression analyses. Descriptions of the independent variables are shown in Table 1.

\section{Statistics}

The trends of stress related to emotional pressure, time pressure, fear of complaints, and work-home interference were tested with a multilevel linear model with repeated measures (procedure Mixed Models $\rightarrow$ Linear in SPSS 14), and reported as unadjusted $\beta$ s (Fig. 1). A similar model tested the changes of stress related to work-home interference over time, adjusted for independent variables (Table 2). Predictors measured at $\mathrm{T} 0$, were first entered in the multivariate analyses. Concurrent explanatory variables were then entered, enabling us to examine the trend of stress over time, controlled for concurrent variables that were measured at all occasions. Interactions between time (T1-T3), and independent concurrent variables that were significant, were entered in the final model. Changes in working hours and children were also tested with a multilevel repeated-measures model, with children and working hours as dependent variables. The effects of independent variables and the mean changes over time of the dependent variables are reported as unstandardized regression coefficients. Participants that were missing at only one time point were included in the multilevel analyses thus reducing the dropout rate compared to general linear models.

\section{Ethics}

To ensure the confidentiality of respondents, Statistics Norway matched participant identity with the data file identity, thus providing only anonymous data to the researchers. This project was conducted according to the guidelines, and with the approval, of the Regional Committee for Medical Research Ethics and the National Data Inspectorate in Norway.

\section{Results}

\section{Course of the four stress dimensions}

Reported stress levels decreased significantly over the observation period in the dimensions of emotional pressure ( $\beta=-0.21, p<0.001)$, time pressure $(\beta=-0.14, p<0.001)$, and fear of complaints $(\beta=-0.24, p<0.001)$ decreased, while the stress related to the work-home interference showed a 
Table 1. Description of variables showing mean values (standard deviation) where not otherwise specified

\begin{tabular}{|c|c|c|c|c|}
\hline & $\begin{array}{l}\text { T0 } \\
\text { Final year } \\
\text { of medical } \\
\text { school }\end{array}$ & $\begin{array}{l}\mathrm{T} 1 \\
\text { Internship }\end{array}$ & $\begin{array}{l}\mathrm{T} 2 \\
\text { Residency }\end{array}$ & $\begin{array}{l}\mathrm{T} 3 \\
\text { 10th year }\end{array}$ \\
\hline Emotional pressure & & $2.4(0.6)$ & $2.1(0.6)$ & $2.0(0.6)$ \\
\hline Time pressure & & $2.6(0.7)$ & $2.5(0.7)$ & $2.4(0.7)$ \\
\hline Fear of complaints & & $2.5(0.7)$ & $2.2(0.7)$ & $2.1(0.7)$ \\
\hline Work-home interference & & $2.4(1.0)$ & $2.5(1.0)$ & $2.6(1.0)$ \\
\hline Number of children ${ }^{\dagger}$ & & $0.4(0.7)$ & $0.9(1.0)$ & $1.8(1.1)$ \\
\hline Working hours a week ${ }^{\dagger \dagger}$ & & $49.5(7.7)$ & $45.6(9.9)$ & $43.6(7.2)$ \\
\hline Spouse support ${ }^{t \dagger \dagger}$ & & $3.8(0.7)$ & $3.7(0.7)$ & $3.7(0.7)$ \\
\hline Colleague support & & $5.6(1.0)$ & $5.1(1.2)$ & $5.0(1.2)$ \\
\hline Neuroticism (scale 0-9) & $3.5(2.3)$ & & & \\
\hline Extraversion (scale 0-9) & $5.6(2.5)$ & & & \\
\hline Conscientiousness (scale $0-9$ ) & $3.1(2.0)$ & & & \\
\hline Age & $28.1(2.8)$ & $29.0(2.8)$ & $31.4(2.4)$ & $37.3(2.7)$ \\
\hline 우/ర(\%) & $58 / 42$ & & $55 / 45$ & $58 / 42$ \\
\hline
\end{tabular}

significant increase in the multivariate analysis in the multilevel repeated measures model $(\beta=0.07, p<0.035)$ uncontrolled (Fig. 1).

\section{Predictors of stress related to work-home interference}

In the final multivariate model, neuroticism $(\beta=0.05$, $p=0.002)$, extraversion $(\beta=0.04, p=0.014)$, and conscientiousness predicted stress related to work-home interference when the other predictors were controlled for (Table 2, block 6). Conscientiousness demonstrated a curvilinear contribution $(\beta=0.02, p=0.006)$. When plotting conscientiousness and stress related to work-home interference we found a J-shaped curve: low and high levels of conscientiousness were related to higher levels of reported stress related to work-home interference, whereas values in the middle of the scale of conscientiousness were related to lower stress. Extraversion and gender remained nonsignificant until the last block in the multilevel model. They became significant when support from spouse and colleagues were entered into the model, thus demonstrating negative confounding. Over time, stress was not related with age. In order to distinguish which of the support measures suppressed extraversion and gender in the multivariate analysis, the support variables were entered separately. Both spouse support and colleague support suppressed the effect of gender and extraversion.
Among the concurrently measured variables, working hours were associated with stress related to work-home interference through their interaction with time. There was an overall reduction in working hours from $\mathrm{T} 1$ to $\mathrm{T} 3,(\beta=-5.7$, $p<0.001)$ and women reduced their working hours more than men, from $49.5 \mathrm{~h}$ per week to an average of $42.3 \mathrm{~h}$ per week, men reduce their hours to $45.6 \mathrm{~h}$ per week (Table 1 ). Number of children was significantly associated with stress related to work-home interference both directly and through the interaction with time. The number of children increased with time $(\beta=1.4, p<0.001$, Table 1$)$. The interaction of children with time became statistically non-significant when spouse support was entered in the final step in the model (Table 2, block 6), showing that this interaction was mediated by spouse support. Spouse support and support from colleagues were negatively correlated to stress related to work-home interference. Women perceived more support from their partners than men $\operatorname{did}(\beta=0.32, p<0.001$, Table 1). Upon entering interactions in the model (Table 2, blocks 3-6) we cannot interpret substantially the main effects directly from Table 2. However, a model including working hours, children and their interactions with time can be specified as

$\mathrm{Y}=\beta 1 \times$ Working hours $+\beta 2 \times$ Working hours $\times$ Time + $\beta 3 \times$ Children $+\beta 4 \times$ Children $\times$ Time 


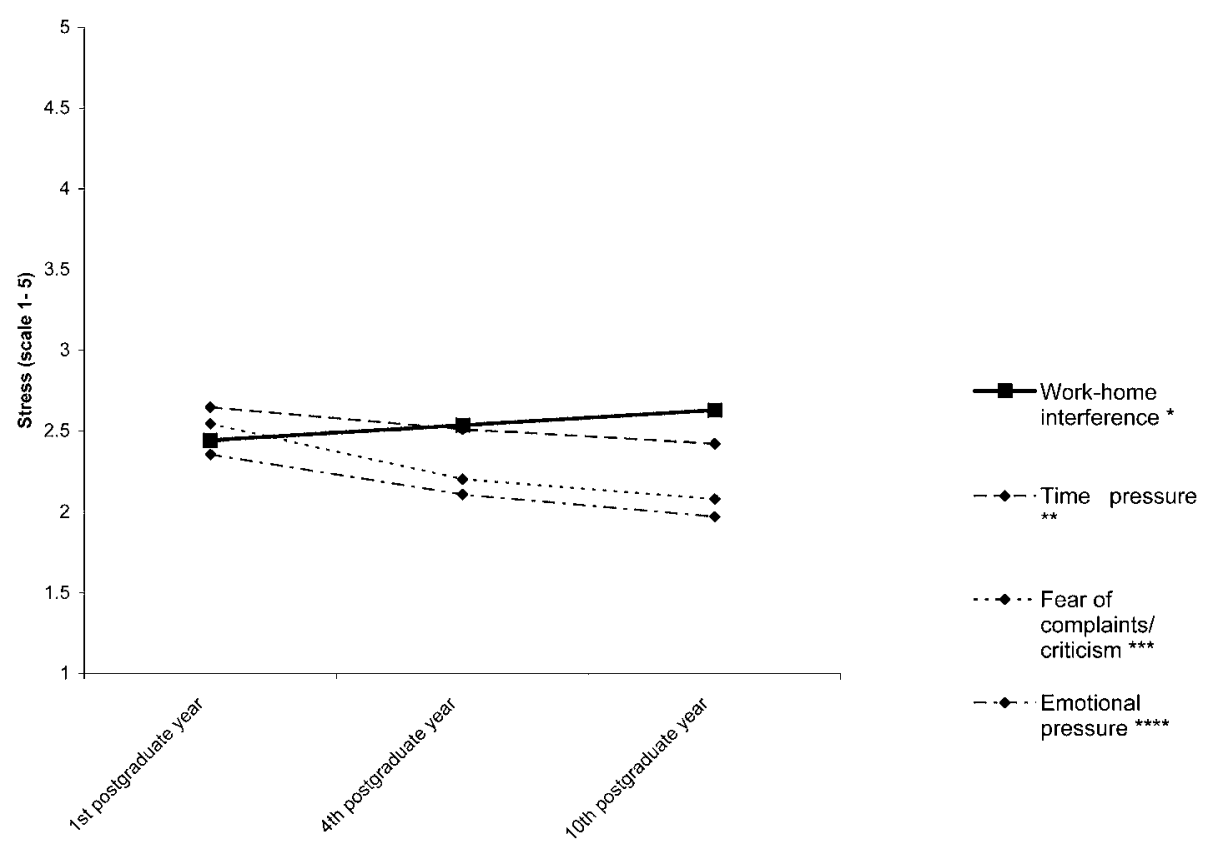

Fig. 1. Trends over time from $\mathrm{T} 1$ to $\mathrm{T} 3$ of the four stress dimensions, unadjusted. Multilevel linear model with repeated measures, unstandardized $\beta$ :

$*$ : Increase T1-T3: $\beta=0.07, p=0.035$; **: Reduction T1-T3: $\beta=-0.14, p<0.001$; ***: Reduction T1T3: $\beta=-0.24, p<0.001 ; * * * *$ : Reduction T1-T3: $\beta=-0.21, p<0.001$.

Exemplified with specific values for working hours and children, where the value of Time is 0 at $\mathrm{T} 1$ (reference) and 1 at T3, we get:

T3, 1 child, 40 h a week: $\mathrm{Y}_{\mathrm{T} 3}=0 \times 40+0.03 \times 40 \times 1+$ $0.42 \times 1-0.22 \times 1 \times 1=1.40$

T1, 1 child, 40 h a week: $\mathrm{Y}_{\mathrm{T} 1}=0 \times 40+0.03 \times 40 \times 0+$ $0.42 \times 1-0.22 \times 1 \times 0=0.42$

thus giving a mean increase of 0.98 points in the score on the work-home interference scale from $\mathrm{T} 1$ to $\mathrm{T} 3$ among those with 1 child and 40 working hours a week. With 1 child, working $45 \mathrm{~h}$ a week give 1.13 point stress increase, working $50 \mathrm{~h}$ give a 1.28 stress increase. For a given number of working hours in our model, e.g. $45 \mathrm{~h}$, the T1-T3 increase in stress was $1.35,1.28,1.06$ and 0.84 points for those with $0,1,2$, and 3 or more children respectively.

\section{Discussion}

Perceived work-home interface stress increased through the first nine years of the medical career in our sample. In contrast to stress related to the work-home interference, the specific patient-work stress related to emotional pressure, time pressure, and fear of complaints decreased with time, possibly due to increased competence and confidence at work. This increase in stress related to work-home interference seems to stem mainly from having children and a lack of reduction in working hours. These results seem to mirror the challenge of balancing work and family demands. Stress related to the work-home interference that results from an increasing number of children may be relieved through a reduction in working hours. Those young physicians that do not manage to reduce working hours over time according to increasing family demands are at risk of experiencing higher levels of stress related to work-home interference. At workplaces, organizational interventions may therefore facilitate such reduction in work hours for those with heavy family burdens.

Our results show that physicians reduce their number of working hours as a trend over time as their family responsibilities grow (increased number of children). Women reduce their working hours more than men, even though they report the same level of family demands as men, in terms of the number of children. This is consistent with the gender role expectation that work is more important for men, but men will then experience the negative influences of work on family life more often than women ${ }^{42,43}$. Gjerberg found that, among Norwegian doctors, more women than men reduced their working hours to accommodate their family responsibilities ${ }^{29)}$. Previous studies have shown little association between long working hours and emotional 
Table 2. Influence of baseline predictors and concurrent variables on stress related to the work-home interference, predictors entered blockwise, in a multilevel repeated measures model, unstandardized regression coefficients

\begin{tabular}{|c|c|c|c|c|c|c|c|c|}
\hline & & $\begin{array}{c}\text { Uni } \\
\text { variate }\end{array}$ & \multicolumn{6}{|c|}{ Multivariate standing blocks } \\
\hline & & $\begin{array}{c}\beta \\
(p \text {-value })\end{array}$ & $\begin{array}{c}\text { Block } 1 \\
\beta \\
(p \text {-value) }\end{array}$ & $\begin{array}{c}\text { Block } 2 \\
\beta \\
\text { (p-value) }\end{array}$ & $\begin{array}{c}\text { Block } 3 \\
\beta \\
(p \text {-value })\end{array}$ & $\begin{array}{c}\text { Block } 4 \\
\beta \\
\text { (p-value) }\end{array}$ & $\begin{array}{c}\text { Block } 5 \\
\beta \\
(p \text {-value })\end{array}$ & $\begin{array}{c}\text { Block } 6 \\
\beta \\
(p \text {-value) }\end{array}$ \\
\hline Repeated & $\begin{array}{l}\text { Time } \\
\mathrm{T} 1 \rightarrow \mathrm{T} 3\end{array}$ & $\begin{array}{l}0.15 \\
(p=0.029)\end{array}$ & $\begin{array}{l}0.16 \\
(p=0.019)\end{array}$ & $\begin{array}{l}0.30 \\
(p<0.001)\end{array}$ & $\begin{array}{l}-0.90 \\
(p=0.042)\end{array}$ & $\begin{array}{l}-1.40 \\
(p=0.002)\end{array}$ & $\begin{array}{l}-1.12 \\
(p=0.016)\end{array}$ & $\begin{array}{l}-1.19 \\
(p=0.017)\end{array}$ \\
\hline \multirow{6}{*}{$\begin{array}{l}\text { Block } 1 \\
\text { Predictors }\end{array}$} & Age & -0.02 & -0.02 & 0.02 & -0.02 & 0.00 & 0.00 & 0.00 \\
\hline & Gender (women) & -0.06 & 0.00 & 0.06 & -0.07 & 0.09 & 0.10 & $\begin{array}{l}0.23 \\
(p=0.002)\end{array}$ \\
\hline & Neuroticism & $\begin{array}{l}0.07 \\
(p<0.001)\end{array}$ & $\begin{array}{l}0.06 \\
(p<0.001)\end{array}$ & $\begin{array}{l}0.06 \\
(p<0.001)\end{array}$ & $\begin{array}{l}0.06 \\
(p<0.001)\end{array}$ & $\begin{array}{l}0.07 \\
(p<0.001)\end{array}$ & $\begin{array}{l}0.07 \\
(p<0.001)\end{array}$ & $\begin{array}{l}0.05 \\
(p=0.002)\end{array}$ \\
\hline & Extraversion & 0.02 & 0.03 & 0.02 & 0.02 & 0.02 & 0.02 & $\begin{array}{l}0.04 \\
(p=0.014)\end{array}$ \\
\hline & Conscientious & 0.02 & $\begin{array}{l}0.12 \\
(p=0.035)\end{array}$ & $\begin{array}{l}-0.15 \\
(p=0.011)\end{array}$ & $\begin{array}{l}-0.15 \\
(p=0.009)\end{array}$ & $\begin{array}{l}-0.16 \\
(p=0.005)\end{array}$ & $\begin{array}{l}-0.16 \\
(p=0.004)\end{array}$ & $\begin{array}{l}-0.13 \\
(p=0.023)\end{array}$ \\
\hline & $\begin{array}{l}\text { Conscientious X } \\
\text { Conscientious }\end{array}$ & & $\begin{array}{l}0.02 \\
(p=0.010)\end{array}$ & $\begin{array}{l}0.02 \\
(p=0.003)\end{array}$ & $\begin{array}{l}0.02 \\
(p=0.002)\end{array}$ & $\begin{array}{l}0.02 \\
(p=0.001)\end{array}$ & $\begin{array}{l}0.02 \\
(p=0.001)\end{array}$ & $\begin{array}{l}0.02 \\
(p=0.006)\end{array}$ \\
\hline Block 2 & $\begin{array}{l}\text { Working hours } \\
\text { (Decreasing } \\
\mathrm{T} 1 \rightarrow \mathrm{T} 3 \text { ) }\end{array}$ & $\begin{array}{l}0.01 \\
(p<0.001)\end{array}$ & & $\begin{array}{l}0.02 \\
(p=0.001)\end{array}$ & 0.01 & 0.01 & 0.00 & 0.01 \\
\hline Block 3 & $\begin{array}{l}\text { Time X } \\
\text { Working hours }\end{array}$ & & & & $\begin{array}{l}0.03 \\
(p=0.006)\end{array}$ & $\begin{array}{l}0.03 \\
(p=0.001)\end{array}$ & $\begin{array}{l}0.03 \\
(p=0.004)\end{array}$ & $\begin{array}{l}0.02 \\
(p=0.020)\end{array}$ \\
\hline Block 4 & $\begin{array}{l}\text { No. children } \\
\text { (Increasing } \\
\mathrm{T} 1 \rightarrow \mathrm{T} 3 \text { ) }\end{array}$ & $\begin{array}{l}0.16 \\
(p<0.001)\end{array}$ & & & & $\begin{array}{l}0.25 \\
(p<0.001)\end{array}$ & $\begin{array}{l}0.42 \\
(p<0.001)\end{array}$ & $\begin{array}{l}0.27 \\
(p<0.001)\end{array}$ \\
\hline Block 5 & $\begin{array}{l}\text { Time X } \\
\text { Children }\end{array}$ & & & & & & $\begin{array}{l}-0.22 \\
(p=0.009)\end{array}$ & -0.04 \\
\hline Block 6 & Spouse support & -0.56 & & & & & & $\begin{array}{l}-0.49 \\
(p<0.001)\end{array}$ \\
\hline & $\begin{array}{l}\text { Colleague } \\
\text { support }\end{array}$ & -0.18 & & & & & & $\begin{array}{l}-0.13 \\
(p<0.001)\end{array}$ \\
\hline
\end{tabular}

$p$-values greater than 0.05 are omitted.

distress ${ }^{44)}$. Although working hours are lower in our sample than in the US and $\mathrm{EU}^{45)}$, we did find that the number of working hours were associated with work-home interface stress. In our study the work hour reduction did not outweigh the growing family demands (number of children) in this period, as reflected in the increase in reported stress from work-home interference.

Neuroticism predicted stress related to the work-home interference in our study (Table 2). This is in accordance with earlier studies, with cross sectional design, where higher levels of neuroticism have been found to correlate with more negative work-home interaction ${ }^{25,32}$. Our study confirms that neuroticism is a significant predictor (and risk factor) of such stress over a $9 \mathrm{yr}$ time span. In the final model shown in Table 2, extraversion emerged as a factor that is related to higher perceived stress related to work-home interference. This relatively small statistical effect emerged after we entered support from colleagues and partners into 
the statistical model, probably indicating that the more extraverted perceive more support than the introverted. Such a finding should be replicated, especially as other studies have shown extraversion to be protective against stress ${ }^{25,33,34)}$. A moderate level of conscientiousness seems to be optimal, whereas physicians with low or high levels of conscientiousness are more prone to stress related to workhome interference. Both high and low conscientiousness and orderliness inherent in the conscientiousness dimension trigger problems with effectively balancing work and family demands.

Female gender became significant in the final step of the multilevel analysis after we entered support from spouse and colleagues. This pattern indicates a negative confounding with support suppressing the effect of gender on stress (Table 2). Women experience more support than men in our study. Others have reported women to experience more stress from the workhome conflict ${ }^{35)}$, and to receive more social support than $m^{36,37)}$. This contrasts our findings where women experience the same level of stress as men and yet perceive more support than men. Differences in utilizing social support has also recently been linked to gender differences in mental health ${ }^{38}$.

In the family domain, we found spouse support to be an important protective variable. Spouse support appears to make conflicts between career and growing family responsibilities more manageable. A supportive spouse may aid the work-home balance through acceptance of the work schedule and through flexibility in taking on family responsibilities. This can alleviate the stress from bad conscience resulting from not prioritizing one's responsibilities at home as well as validate the decisions made. Emotional support may also relieve stressful experiences at work that may spill over to the family domain. In a Norwegian sample, Gjerberg found that physicians were satisfied with their spouse support ${ }^{29)}$. The women felt more emotional support, whereas the men experienced more instrumental support, but also more conflict. Our results showed that the effect of an increasing number of children with time became non-significant when spouse support was entered into our model. Thus, in addition to having a direct effect on work-home interference, we see that spouse support indirectly counteracts this stress through attenuating the stressing effect of an increasing number of children.

Support from colleagues protected against stress related to work-home interference in our study, although to a lesser degree than spouse support. Support from colleagues has been emphasized in earlier studies as helpful in handling long hours and stress ${ }^{39,40)}$. The availability of supportive colleagues may be beneficial for doctors when balancing work and family life, in both confirmation of stressful experiences, which has proved to reduce stress ${ }^{41}$, and in instrumental support (e.g., smoothing of working conditions). These work-related factors are all important, as they may be subject to interventions at an organizational level.

\section{Strengths and limitations}

The longitudinal design and the representative nationwide sample are strengths of this study. The large number of respondents allowed us to perform multivariate analysis. The response rate was acceptable, but the loss of follow up in the study may have produced type II errors due to loss of statistical power. On the question of whether the missing data may be related to our outcome of interest we do not know if those who dropped out would have reported high levels of stress at follow-up, explaining some of the decrease in stress related to emotional pressure, time pressure or fear of complaints, i.e. the healthy worker effect giving a skewed result. We do know that the dropouts did not report higher job stress at $\mathrm{T} 1$ than non-dropouts and this finding makes the healthy worker effect less probable. The data are also used optimally in the multilevel repeated measures analyses which include participants that are missing at only one of the three time points. The generalizability of the results across countries may be limited by the number of working hours, which is lower in Norway than in countries such as the US.

\section{Conclusion}

Overall, this study suggests that stress related to the workhome interference increases through the first $9 \mathrm{yr}$ of physicians' careers, in contrast to decreasing specific patientwork stressors. Lack of reduction in working hours and having many children predicted an increase in stress related to the work-home interference. Personality traits of neuroticism and conscientiousness were also risk factors for stress related to the work-home interference, whereas support from a partner and colleagues were negatively associated with such stress.

\section{Acknowledgements}

We would like to acknowledge Kristine Finset for preparation of the data files, and Associate Professor Magne Thoresen, University of Oslo, for valuable advice in the use of multilevel repeated measures models. This project was financed with the aid of EXTRA funds from the Norwegian Foundation for Health and Rehabilitation. 


\section{References}

1) Shanafelt TD, Sloan JA, Habermann TM (2003) The wellbeing of physicians. Am J Med 114, 513-9.

2) Mitchell M, Srinivasan M, West DC, Franks P, Keenan C, Henderson M, Wilkes M (2005) Factors affecting resident performance: development of a theoretical model and a focused literature review. Acad Med 80, 376-89.

3) Baldwin PJ, Dodd M, Wrate RM (1997) Young doctors' health-II. Health and health behaviour. Soc Sci Med 45, 41-4.

4) Firth-Cozens J (1987) Emotional distress in junior house officers. BMJ 295, 533-6.

5) Hsu K, Marshall V (1987) Prevalence of depression and distress in a large sample of Canadian residents, interns, and fellows. Am J Psychiatry 144, 1561-6.

6) Tyssen R, Vaglum P (2002) Mental health problems among young doctors: an updated review of prospective studies. Harv Rev Psychiatry 10, 154-65.

7) Reuben DB (1985) Depressive symptoms in medical house officers. Effects of level of training and work rotation. Arch Intern Med 145, 286-8.

8) Kapur N, Borrill C, Stride C (1998) Psychological morbidity and job satisfaction in hospital consultants and junior house officers: multicentre, cross sectional survey. BMJ 317, 5112.

9) Baldwin PJ, Dodd M, Wrate RW (1997) Young doctors' health-I. How do working conditions affect attitudes, health and performance? Soc Sci Med 45, 35-40.

10) Cooper CL, Rout U, Faragher B (1989) Mental health, job satisfaction, and job stress among general practitioners. BMJ 298, 366-70.

11) Firth-Cozens J, Morrison LA (1989) Sources of stress and ways of coping in junior house officers. Stress Med 5, 1216.

12) Tyssen R, Vaglum P, Grønvold NT, Ekeberg $\varnothing$ (2000) The impact of job stress and working conditions on mental health problems among junior house officers. A nationwide Norwegian prospective cohort study. Med Educ 34, 374 84.

13) Richardsen AM, Burke RJ (1991) Occupational stress and job satisfaction among physicians: sex differences. Soc Sci Med 33, 1179-87.

14) Tyssen R, Vaglum P, Gronvold NT, Ekeberg O (2001) Suicidal ideation among medical students and young physicians: a nationwide and prospective study of prevalence and predictors. J Affect Disord 64, 69-79.

15) Evans J, Goldacre MJ, Lambert TW (2000) Views of UK medical graduates about flexible and part-time working in medicine: a qualitative study. Med Educ 34, 355-62.

16) Linn LS (1981) Career orientations and the quality of working life among medical interns and residents. Soc Sci Med 15, 259-63.

17) Allen TD, Herst DE, Bruck CS, Sutton M (2000)
Consequences associated with work-to-family conflict: a review and agenda for future research. J Occup Health Psychol 5, 278-308.

18) Netemeyer RG, Boles JS, McMurrian R (1996) Development and validation of work-family conflict and family-work conflict scales. J Appl Psychol 81, 400-10.

19) Geurts S, Rutte C, Peeters M (1999) Antecedents and consequences of work-home interference among medical residents. Soc Sci Med 48, 1135-48.

20) Firth-Cozens J, Moss F (1998) Hours, sleep, teamwork, and stress. Sleep and teamwork matter as much as hours in reducing doctors' stress. BMJ 317, 1335-6.

21) Carlson DS, Perry JC (1999) The role of social support in the stressor-strain relationship: an examination of work-family conflict. J Manage 25, 513-40.

22) Linzer M, Visser MR, Oort FJ, Smets EM, McMurray JE, de Haes HC (2001) Predicting and preventing physician burnout: results from the United States and the Netherlands. Am J Med 111, 170-5.

23) Firth-Cozens J (1997) Predicting stress in general practitioners: 10 year follow up postal survey. BMJ 315, 345.

24) Berntsson L, Lundberg U, Krantz G (2006) Gender differences in work-home interplay and symptom perception among Swedish white-collar employees. J Epidemiol Community Health 60, 1070-6.

25) Grzywacz JG, Marks NF (2000) Family, work, work-family spillover, and problem drinking during midlife. J Marriage Fam 62, 336-48.

26) Vollrath M (2001) Personality and stress. Scand J Psychol 42, 335-47.

27) Tyssen R, Dolatowski F, Røvik JO, Thorkildsen RF, Ekeberg $\varnothing$, Hem E, Gude T, Grønvold NT, Vaglum P (2007) Personality traits and types predict medical school stress: a six-year longitudinal and nationwide study. Med Educ 41, 781-7.

28) Tyssen R, Vaglum P, Grønvold NT, Ekeberg $\varnothing$ (2005) The relative importance of individual and organizational factors for the prevention of job stress during internship: a nationwide and prospective study. Med Teach 27, 726-31.

29) Gjerberg E (2003) Women doctors in Norway: the challenging balance between career and family life. Soc Sci Med 57, 1327-41.

30) Kristiansen IS, Forde OH, Aasland O, Hotvedt R, Johnsen R, Forde R (2001) Threats from patients and their effects on medical decision making: a cross-sectional, randomised trial. Lancet 357, 1258-61.

31) Torgersen $S$ (1980) Hereditary-environmental differentiation of general neurotic, obsessive, and impulsive hysterical personality traits. Acta Genet Med Gemellol 29, 193-207.

32) Cox DR, Wermouth N (1994) Tests of Linearity, Multivariate Normality and the Adequacy of Linear Scores. Appl Statist 43, 347-55.

33) Beauregard TA (2006) Predicting interference between work and home: a comparison of dispositional and situational antecedents. J Manage Psychol 21, 244-64. 
34) Costa PTJ, Sommerfield MR, McCrae RR (1996) Personality and coping: a reconceptualization. In: Handbook of coping, Zeidner M and Endler NS (Eds.), 44-61, John Wiley, New York.

35) Lischetzke T, Eid M (2006) Why extraverts are happier than introverts: the role of mood regulation. J Pers 74, 1127-62.

36) Dumelow C, Littlejohns P, Griffiths S (2000) Relation between a career and family life for English hospital consultants: qualitative, semistructured interview study. BMJ 320, 1437-40.

37) Belle D (1987) Gender differences in the social moderators of stress. In: Gender and Stress, Barnett R, Biener L and Baruch G (Eds.), 257-77, Free Press, New York.

38) Gross EB (1992) Gender differences in physician stress. J Am Med Wom Assoc 47, 107-12.

39) Kendler KS, Myers J, Prescott CA (2005) Sex differences in the relationship between social support and risk for major depression: a longitudinal study of opposite-sex twin pairs. Am J Psychiatry 162, 250-6.
40) Sonnetag S (1996) Work group factors and individual wellbeing. In: Handbook of work group psychology, West M (Ed.), Wiley, Chichester.

41) Paice E, Moss F, Heard S, Winder B, McManus IC (2002) The relationship between pre-registration house officers and their consultants. Med Educ 36, 26-34.

42) Lazarus RS (1999) Stress and emotion. A new synthesis, 2nd Ed., Springer Publishing Company, Inc., Chippenham.

43) Frone MR, Russell M, Cooper ML (1992) Antecedents and outcomes of work-family conflict: testing a model of the work-family interface. J Appl Psychol 77, 65-78.

44) Pleck JH (1992) The work-family role system. Soc Probl 24, 417-27.

45) Firth-Cozens J, Cording H (2004) What matters more in patient care? Giving doctors shorter hours of work or a good night's sleep? Qual Saf Health Care 13, 165-6.

46) Oransky I (2003) Limits imposed on residents' work hours. Lancet 362, 378-9. 
Appendix 1 Factor analysis of the modified Cooper job stress questionnaire, rotated matrix solution

\begin{tabular}{|c|c|c|c|c|c|}
\hline & & I & II & III & IV \\
\hline I. & Emotional pressure & & & & \\
\hline 1. & Dealing with the terminally ill and their relatives & 0.76 & 0.01 & 0.17 & -0.01 \\
\hline 2. & Daily contact with dying and chronically ill patients & 0.72 & 0.04 & 0.14 & 0.06 \\
\hline 3. & Taking care of suffering patients & 0.71 & 0.09 & 0.17 & 0.00 \\
\hline 4. & Twenty four hour responsibility for patients' lives & 0.58 & 0.36 & 0.11 & 0.22 \\
\hline 5. & Emotionally engaged with the patients & 0.56 & 0.14 & 0.32 & 0.14 \\
\hline 6. & Dealing with problem patients & 0.56 & 0.33 & 0.17 & 0.01 \\
\hline 7. & Fear of making mistakes ${ }^{\dagger}$ & 0.53 & 0.31 & 0.35 & 0.17 \\
\hline 8. & Conducting surgery & 0.53 & 0.07 & 0.01 & 0.06 \\
\hline 9. & Being in a state of readiness & 0.51 & 0.31 & 0.08 & 0.24 \\
\hline 10. & Unrealistically high expectations by others of your role ${ }^{\dagger}$ & 0.41 & 0.35 & 0.16 & 0.20 \\
\hline 11. & Taking several samples in a short time ${ }^{\dagger}$ & 0.35 & 0.31 & 0.12 & 0.11 \\
\hline II. & Time pressure & & & & \\
\hline 1. & Interruptions and fuss at work & 0.11 & 0.66 & 0.29 & 0.06 \\
\hline 2. & Time pressure & 0.08 & 0.63 & 0.18 & 0.08 \\
\hline 3. & Admissions & 0.28 & 0.63 & 0.04 & 0.06 \\
\hline 4. & Medical records and paperwork & 0.00 & 0.60 & 0.12 & 0.00 \\
\hline 5. & Remaining alert when on call ${ }^{\dagger}$ & 0.42 & 0.58 & -0.01 & 0.08 \\
\hline 6. & Working environment & 0.11 & 0.54 & -0.07 & 0.17 \\
\hline 7. & Night calls & 0.32 & 0.53 & 0.04 & 0.16 \\
\hline III. & Fear of complaints and criticism & & & & \\
\hline 1. & Worrying about patients' complaints & 0.20 & 0.15 & 0.68 & -0.02 \\
\hline 2. & No appreciation of your work by patients & 0.07 & 0.11 & 0.66 & -0.04 \\
\hline 3. & Adverse publicity by media & -0.02 & 0.24 & 0.59 & 0.02 \\
\hline 4. & Dealing with relatives as patients & 0.28 & -0.26 & 0.55 & 0.29 \\
\hline 5. & Dealing with friends as patients & 0.27 & -0.31 & 0.55 & 0.32 \\
\hline 6. & Fear of litigation ${ }^{\dagger}$ & 0.37 & 0.23 & 0.49 & 0.16 \\
\hline 7. & $\begin{array}{l}\text { Expectations that the physician should deal } \\
\text { with non-medical problems }\end{array}$ & 0.15 & 0.17 & 0.47 & 0.11 \\
\hline 8. & Conflicts with colleagues or other staff & 0.12 & 0.03 & 0.43 & 0.20 \\
\hline IV. & Work-home interference & & & & \\
\hline 1. & Demands of your job on family life & 0.03 & 0.20 & -0.06 & 0.80 \\
\hline 2. & Balancing oneself between work and private life & 0.01 & 0.26 & 0.01 & 0.77 \\
\hline 3. & Demands of your job on social life & 0.14 & 0.34 & 0.10 & 0.71 \\
\hline 4. & Worry about own finances ${ }^{\dagger}$ & 0.07 & 0.03 & 0.12 & 0.50 \\
\hline 5. & Thinking about possible unemployment ${ }^{\dagger}$ & 0.08 & -0.09 & 0.23 & 0.42 \\
\hline 6. & Economy decisions during work as physician ${ }^{\dagger}$ & 0.24 & -0.02 & 0.29 & 0.42 \\
\hline
\end{tabular}

${ }^{\dagger}$ Excluded items, due to loading $<0.2$, or loading differences between factors of less than 0.2 , or due to differing face validity (item IV-4) 